\title{
Effect of Basketball Specific Repeated - Sprint Training On Aerobic Capacity of Male Basket Ball Players
}

\author{
N. Rajendra, \\ Research Scholar, Department of Physical Education and Sports Sciences, Yogi veman University, Kadapa- \\ 516003, India.
}

\begin{abstract}
The purpose of this study is to assess the effect of Basketball specific repeated - sprint training on aerobic capacity of male Basketball players. To achieve the purpose of the study thirty male basketball players were selected randomly from Department of Physical Education and Sports Sciences, Yogi veman University, Kadapa. The selected subjects were assigned into 2 groups: basketball specific repeated - sprint training group $(n=15)$ and control group $(n=15)$. The selected subjects mean age: $23.15 \pm 3.00$ years; weight: $68.74 \pm 7.25 \mathrm{~kg}$ and height: $176.37 \pm 7.67 \mathrm{~cm}$. The criterion variable selected in this study was aerobic capacity which was measured by multistage fitness test. The basketball specific repeated - sprint training group underwent eight weeks of training. Pre and post aerobic capacity was measured on the indoor. The data was analysed using Analysis of co-variance (ANCOVA). The result of the study showed post test $(F=20.13)$ and adjusted post test mean $(F=10.68)$ showed significant $(p<0.05)$ difference among repeated - sprint training group and control group on aerobic capacity. It is concluded that basketball specific repeated sprint training for eight weeks is more effective in increasing aerobic capacity of men Basketball players. The training load adopted in repeated - sprint training which resulted in $11.79 \%$ of changes in aerobic capacity.
\end{abstract}

Keywords: Repeated, Sprint, Basket ball, Aerobic capacity

\section{Introduction}

Basketball is a modern ball game which belongs to the family of team sports. It combines the best features of different branches of sport, that is, the advantages of physical abilities, technical skills and tactical knowledge. It is a strenuous body contact Olympic team sport that places emphasis on running, jumping, sprinting, throwing, hitting, blocking, and pushing. It's a team sports which require a high standard of preparation in order to complete sixteen minutes of competitive play and to achieve success. In this game movement patterns are characterized as intermittent and change continuously in response to different offensive and defensive situations in which anthropometric characteristics and high levels of strength, muscle power, aerobic capacity and basketball throwing velocity are the most important factors that give a clear advantage for successful participation in elite levels of Basketball leagues (Bobbert and Van Ingen Schenau, 1988).

Training is any organized and regular activity done for increasing the performance of athletes and are divided into different kinds considering the performance requirements of athletes. Repeated-sprint ability (RSA)-based training is characterized by performing repeated sprints with minimal recovery between sprint bouts (i.e., 10-20 maximal sprints or shuttle sprints of $\leq 10$ seconds, with brief recovery periods ( $\leq 60$ seconds); work : rest ratio of 1:4 or 1:6) (Fernandez-Fernandez et al. 2012). During such training, there is an increase in the activity of some anaerobic enzymes, which leads to a higher rate of anaerobic energy turnover and increases the number of muscle membrane transport proteins involved in $\mathrm{pH}$ regulation and muscle capillarization and in some cases enhances the muscle buffering capacity. Also, the performance of maximal or near-maximal shortterm can lead to higher $\mathrm{VO} 2 \mathrm{max}$ values and an increased aerobic enzyme activity (Fernandez-Fernandez et al. 2012). These findings suggest the effectiveness of repeated-sprint for enhancing aerobic capacity. The purpose of this study is to assess the effect of basket ball specific repeated - sprint training on aerobic capacity of male basketball players.

\section{Subjects and variable}

\section{Methods}

To accomplish the purpose of the study thirty male Basketball players were selected randomly from Department of Physical Education and Sports Sciences, Yogi vemana University, kadapa. The selected subjects were assigned into 2 groups: basket ball specific repeated - sprint training group $(n=15)$ and control group $(\mathrm{n}=15)$. The selected subjects mean age: $23.15 \pm 3.00$ years; weight: $68.74 \pm 7.25 \mathrm{~kg}$ and height: $176.37 \pm 7.67 \mathrm{~cm}$. The criterion variable selected in this study was aerobic capacity which was measured by multistage fitness test. 
Effect of Basketball Specific Repeated - Sprint Training On Aerobic Capacity of Male Basket Ball ..

\section{Training}

Basketball specific repeated sprint training program was performed 3 day per week for eight weeks. They perform 3 sets and each set constitutes of 10 repetition totally they perform 30 repetitions. They ran for 30 meter distance while running they perform four passes, one dribble and end with jump shot. They were given 15 seconds of passive recovery between the repetitions and 150 seconds rest between the set. The players were instructed to perform at high intensity. In this the players passing, dribbling and shooting abilities were incorporated simultaneously along with sprint.

\section{Statistical technique}

The experimental design used for the present investigation was Analysis of Covariance (ANCOVA). Since two groups are involved post hoc test was not applied to determine the significant paired mean differences. The level of confidence was fixed at 0.05 to test the significance. The data was analyzed in computer system by using statistical package for social science (SPSS) version 17.

Figure 1: Basketball specific repeated sprint training

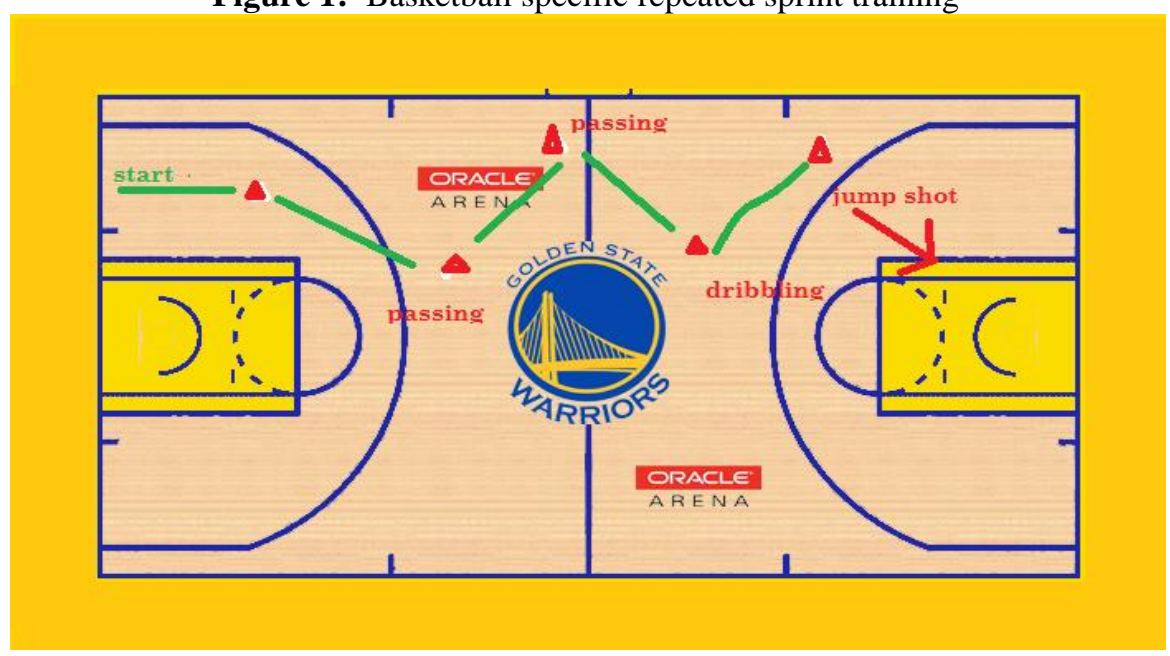

\section{Results}

It is clear from the table 1 that there is no significant difference between Basketball specific repeated sprint training and control group on aerobic capacity before commencement of training, as obtained $F$ ratio of 3.79 is less than the required table value of 4.196 at $\square=0.05$ for the df of 1 and 28 . It denotes that the random assignment of subjects for the two groups is successful, however initial difference not elicited. Table 2 also reveals that there is a significant difference on aerobic capacity during post test. The obtained $F$ ratio of 20.13 is greater than the required table value of 4.196 at $\square=0.05$ for the df of 1 and 28 . Thereby it infers that the aerobic capacity found increase significantly before and after eight weeks of basketball specific repeated sprint training.

Table 1: Summary of ANCOVA on aerobic capacity

\begin{tabular}{|c|c|c|c|c|c|}
\hline Testing Conditions & SOV & SS & df & MS & $\boldsymbol{F}$ \\
\hline \multirow{2}{*}{$\begin{array}{l}\text { Pre } \\
(\mathrm{M} \pm \mathrm{SD})\end{array}$} & Between & 73.54 & 1 & 73.54 & \multirow[t]{2}{*}{3.79} \\
\hline & Within & $53.28 /$ & 28 & 19.40 & \\
\hline \multirow{2}{*}{$\begin{array}{l}\text { Post } \\
(\mathrm{M} \pm \mathrm{SD})\end{array}$} & Between & 72.27 & 1 & 72.27 & \multirow[t]{2}{*}{$20.13 *$} \\
\hline & Within & 100.7 & 28 & 3.59 & \\
\hline \multirow{2}{*}{$\begin{array}{l}\text { Adjusted } \\
\text { (M) }\end{array}$} & Between & 22.04 & 1 & 22.04 & \multirow[t]{2}{*}{$10.68^{*}$} \\
\hline & Within & 55.72 & 27 & 2.063 & \\
\hline
\end{tabular}

*Significant at 0.05 level of confidence

Further, table 1 clearly shows that aerobic capacity between the groups was significant, as obtained $F$ ratio of 10.68 is greater than the required table value of 4.210 at $\square=0.05$ for the df of 1 and 27 , indicating that after adjusting pre-test scores, there was a significant difference between the two groups on adjusted post test scores on aerobic capacity. The findings of the study shows that higher aerobic capacity was recorded in basket ball specific repeated sprint training $(\mathrm{M}=56.71)$ when compared to control group $(\mathrm{M}=50.88)$. Thus, it is concluded that eight weeks of Basketball specific repeated sprint training significantly increased aerobic capacity by $11.79 \%$ than control group. The changes in aerobic capacity are presented graphically in figure. 


\section{Discussion}

In the present study Basket ball specific repeated sprint training protocols elicited improvements in aerobic capacity. In this regard, recent studies using sprint training have reported significant increases in both anaerobic and aerobic power (Ferrauti, Kinner \& Fernandez-Fernandez 2011), which can be related to increases in glycolytic (Linossier et al. 1997) and oxidative enzyme activities (Burgomaster, Heigenhauser \& Gibala 2006; Burgomaster et al. 2008; Burgomaster et al. 2005), muscle buffering capacity (Bishop et al. 2009; Dawson et al. 1998; Edge et al. 2006), and/or ionic regulation (Burgomaster et al. 2008; Rodas et al. 2000). The improvement in aerobic fitness after the basket ball specific repeated sprint training protocol is consistent with the findings of previous studies using sprint-based training protocols (Dawson et al. 1998; Ferrari-Bravo et al. 2007; Hazzell et al. 2010; MacDougall et al. 1998; Rodas et al. 2000). The present results support the conclusions of Gibala et al. (2004) that Basketball specific repeated sprint training might be a time-efficient training strategy in enhancing aerobic adaptations and maintenance of skill ability in Basketball players.

\section{Conclusion}

It is concluded that Basket ball specific repeated sprint training programs might be appropriate to optimize the development of cardio respiratory fitness in Basketball players. In terms of practicability, it seems that Basketball specific repeated sprint training might be a time efficient training strategy in enhancing aerobic adaptations, given the better adaptations (i.e., Basketball specific endurance and skill).

\section{References}

[1]. Bishop, D., Edge, J., Mendez-Villanueva, A., Thomas, C., and Schneiker, K. (2009). High-intensity exercise decreases muscle buffer capacity via a decrease in protein buffering in human skeletal muscle. Pflugers Arch, 458: 929-936.

[2]. Bobbert, M.F. and Van Ingen Schenau, G.J. (1988). Coordination in vertical jumping. J Biomech, 21:249-62

[3]. Burgomaster, K.A., Heigenhauser, G.J., and Gibala, M.J. (2006). Effect of short term sprint interval training on human skeletal muscle carbohydrate metabolism during exercise and time-trial performance. J Appl Physiol, 100: 2041-2047.

[4]. Burgomaster, K.A., Howarth, K.R., Phillips, S.M., Rakobowchuk, M., MacDonald, M.J., McGee, S.L., and Gibala, M.J. (2008). Similar metabolic adaptations during exercise after low volume sprint interval and traditional endurance training in humans. $J$ Physiol, 586: 151-160.

[5]. Burgomaster, K.A., Hughes, S.C., Heigenhauser, G.J., Bradwell, S.N., and Gibala, M.J. (2005). Six sessions of sprint interval training increases muscle oxidative potential and cycle endurance capacity in humans. J Appl Physiol, 98: 1985-1199.

[6]. Dawson, B., Fitzsimons, M., Green, S., Goodman, C., Carey, M., and Cole, K. (1998). Changes in performance, muscle metabolites, enzymes and fibre types after short sprint training. Eur J Appl Physiol Occup Physiol, 78: 163-169.

[7]. Edge, J., Bishop, D., Hill-Haas, S., Dawson, B., and Goodman, C. (2006). Comparison of muscle buffer capacity and repeatedsprint ability of untrained, endurance- 